\title{
Measuring Social Personas
}

\author{
Gulcimen Yurtsever \\ Business Department, Uşak University, Uşak, Turkey \\ Email: gulcimenyurtsever@gmail.com
}

How to cite this paper: Yurtsever, G. (2020). Measuring Social Personas. Open Journal of Social Sciences, 8, 111-124.

https://doi.org/10.4236/jss.2020.86011

Received: May 7, 2020

Accepted: June 6, 2020

Published: June 9, 2020

Copyright $\odot 2020$ by author(s) and Scientific Research Publishing Inc. This work is licensed under the Creative Commons Attribution International License (CC BY 4.0).

http://creativecommons.org/licenses/by/4.0/

\begin{abstract}
This study's goal was to develop a valid and reliable scale for measuring "personas". Three different samples with self-report scales were used. Samples from Studies 1 and 2 produced similar factor loadings for all items. The results of the two studies supported a four-factor solution for the persona scale as follows: social mask, social influence, identity, and role. To assess criterion validity, the correlation between peer evaluations and persona scales was analyzed. To assess criterion validity, the correlation between peer evaluations and persona scales was analyzed. Samples from Study 3 indicate that the scale was valid. The internal consistency of the persona scale indicated that the scale had satisfactory reliability, and results of a test-retest suggested that responses on the scale were stable. The most important contribution of this research to persona theory is the explanation of persona personalities. How does a high or low persona personality affect the organization, for example, through creativity, harmony, or negotiation ability? This scale helps investigate these questions.
\end{abstract}

\section{Keywords}

Persona, Masks, Identity, Influence, Role

\section{Measuring Social Personas}

The word "persona" was originally used in Latin in reference to a theater mask. According to Jungian psychology, a persona (plural "personae" or "personas") wears a social mask to satisfy the demands or expectations of a certain social situation. "A persona is ... a functional complex that comes into existence for reasons of adaption or personal convenience" (Jung, 2014: p. 801). Jung (1966) claimed that a persona is a created character of a person and a role one assumes to ensure community acceptance, including at work, with friends, and at home. Personas can create specific situations, because they place more emphasis on social interaction. Jung warned that people who rely too much on contrived per- 
sonas for different social roles risk losing their own personality traits. Jackson (2017) argued that using different personas to play social roles can leave a person unstable. Essentially, people using personas have modified their sense of self for the sake of others. In general, it is during public interaction when people adapt themselves to present their public image as they desire.

Social masks, identity, social influence, and role, which are common concepts in social psychology, have been investigated (e.g. Baber \& Tucker, 2006; Barbara, 2018; De Gere, 2008; Millington, 1982; Nario-Redmond et al., 2004). This research was neither with testing hypotheses about persona nor with the empirical research of problem areas in which persona was one of many relevant variables to be taken into consideration. Rather, it is with the investigation of persona as an interesting variable of its own right, and the attempt was made in this study to explain its component dimensions, to construct measure on the basis of these dimensions.

The development of a scale is supported by solid concepts and a more stable and reliable foundation of related knowledge (Miller-Carpenter, 2018). Therefore, the current study concentrated on developing a scale that measures certain factors that comprise a persona.

Persona-related research can be divided into three groups: 1) persona studies investigating individual identities of personas (e.g., Higgins \& McKay, 2015; Maria \& Sandoval, 2008; Arendt, 2000), 2) studies investigating personas in the context of digital marketing (e.g., Salminen et al., 2018; An, Kwak, \& Jansen, 2017; Friess, 2012; Goodwin, 2009; Oyd, Jones, \& Twidalei, 2008) and 3) studies investigating personas in the context of human-computer interaction (Friess, 2012; Wilson, 2009). The main point of in this study is that we apply the psychological definition of personas as a public identity, whereas human-computer interaction and marketing studies assume personas to be imaginary people describing real target groups.

Most persona studies investigate how individuals enter social spaces and present themselves (e.g., Broady, 2015; Gergen, 1972; Haakonssen, 2014; Leary, 2003; Robinson, 2009; Higgins \& McKay, 2015; Marshall, Moore, \& Borbour, 2015). Some researchers claim that the unique transformations and variability between different social settings may require more adaptive people. For this study, we reviewed literature related to personas to construct a measuring scale. The literature suggested that there are four important factors in persona: social mask (Jung, 1966), social influence (Jackson, 2017), identity (Griffith \& Hastings, 2014) and role (del Río-Lozano et al., 2013). These four factors are explained below.

Social masking is defined as the deliberate attempt to conceal one's emotions by portraying another emotion (De Gere, 2008) in order to adapt to a role perceived to meet certain social standards better (Goffman, 1959). According to Jung (1971), people use social masks to influence their social environment. Hillman (1992) notes that the aim of a persona is to protect the person's "true face". In this sense, one's persona mask serves as the social face. Darby and 
Chatterton (2019) found in their research that social entrepreneurs and social activists wear social masks to manage constant change and dynamic interaction. Chatterton (2019) noted that people wear masks to conceal certain personality traits to fit or avoid situations. Jackson (2017) claimed that when a persona becomes more socially acceptable than the actual person, its value increases because the persona mask becomes the conduit that converses between the true self and the social world. The essence of masking one's true self is to foster more desirable social impressions and experience broader social approval.

Social influence refers to a person's ability to alter the attitudes or behavior of others (Burger, 2001) in different forms, including obedience, conformity, persuasion, and peer pressure (Izuma, 2017). These personas attempt to influence others, and their effectiveness will vary based on context (Khashea, Becerik-Gerbera, \& Grat, 2017). Goffman (1959) stated that individuals are constantly acting to influence others and to prevent embarrassment. Life is a their an environment for most of us. In this sense, we might say that personas are mental models created to obtain approval from others. For example, both Gergen (1972) and Paulhus and Malcolm (1988) claimed that a socially flexible personality enables individuals to act easily in response to the demands of a dynamic social life. Meanwhile, it has been argued that irregular social events and contexts may create a maladaptive and vulnerable sense of self (e.g. Baird, Le, \& Lucas, 2006; Maslow, 1968). In a person's development, authenticity is important, which includes living preferences that give voice to one's own feelings, ideas, and values (Maslow, 1968; Rogers, 1959).

In a social sense, "an identity refers simply to a social category, a set of persons marked by a label and distinguished by rules deciding membership and (alleged) characteristic features or attributes" (Fearon, 1999: p. 2). Behavior is most important between group relationships and group identification (Hornung, Bandelow, \& Vogeler, 2019). Individuals try to maintain positive identities in society by comparing themselves to others within social groups (Hogg, Abrams, \& Brewer, 2017). However, people may lose their real personal identities when trying to develop more positive impressions for specific social and personal areas (Griffith \& Hastings, 2014). When persons lose their own identity, they may reach a point where they are unable to act outside of their fabricated personas (Jackson, 2017). Jung (1966) noted that overusing the persona "tactic" might result in the loss of one's individuality. The worst thing for a "persona person" is becoming nothing more than a vessel for the unconscious (Hillman, 1992). Persona identification occurs when an individual's ego begins to relate to his/her persona and not to oneself. Persons using personas frequently suffer from unstable personalities if they must continually adapt for the sake of others (Hopcke, 1995). However, their advantage is the ability to communicate with others with little effort (Holtzblatt, Wendell, \& Wood, 2005).

A role refers to a set of connected behaviors, obligations, beliefs, and norms that form the social perception of individuals in a social situation (Biddle, 1986). People will develop personas featuring timely personality traits that are suitable 
for specific roles (Hudson, 1978). They are motivated by social acceptance to maintain feelings of worth. Jung noted that social influences contribute to the development of sexual roles and gender identities. The aim of the persona is to prevent social rejection (Jung, 1966), and people may create numerous personas to identify with different roles in their social experiences as well as other functions and responsibilities (del Río-Lozano et al., 2013). To adopt several roles or mask one's true personality may comprise some part of their personality, but it is not the entire personality of personas (Broady, 2015).

\section{Methods}

\subsection{The Development of the Persona Scale}

Based on the literature review, twenty-seven items were selected for the persona scale. The persona questionnaire began with the following statement: My behaviors are largely moulded by society. The items of this scale used four different persona terms: social mask, social influence, identity, and role. Typical items were, "I present myself to others in a fashion that they believe I should", "I am motivated by social acceptance to maintain feelings of worth" and "I have no difficulty playing the expected professional role, thanks to my experience".

To assess content validity, they were submitted to a panel of expert judges. The panel included two professors of psychology, two experts in sociology, and two experts in human resources. The judges were given written materials describing the persona concept and definition of important factors in persona (see above).

They indicated their opinions based on a seven-point scale $(1=$ "no" to $7=$ "strongly agree"). The Cronbach's alpha measure of interrater reliability is the same as the demand for alpha as a measure of internal consistency where over .70 acceptable (Stemler, 2004). The mean interrater reliability coefficient of the judges' opinions was .93. The results show that fourteen of the twenty-seven persona items were represented for this scale. These fourteen were translated into English (see Appendix 2) and then into Turkish by a different translator to ensure the accuracy of meanings.

\subsection{Participants}

Three studies were conducted to achieve the research goals. Sample 1 consisted of 226 lower- and middle-level managers at a bank in Izmir, Turkey. All were university graduates with at least eight years of work experience. The average age of the participants was thirty-seven. The snowball sampling method was used to recruit the participants. In this study, bank employees were selected as a sample because they tend to wear more social masks to avoid conflicts with customers (Bourdieu, 2005; Nash, \& Calanico, 1996). Written informed consent was obtained from all participants.

The sample 2 consisted of 110 administrative staff ( 60 women and 50 men) of universities in Turkey. Their mean age was $34 . \mathrm{O}(\mathrm{SD}=3.6)$. The snowball sam- 
pling method was as used to recruit the participants.

Snowball sampling does not rely on sampling frame (Biernacki \& Waldorf, 1981). Kirchherr and Charles (2018) suggested that in order to increase diversity, sample diversity should be used. In order to ensure sample diversity we used three different samples: 1) Bank 2) University 3) Students.

The participants of Study 3 included fifty-nine female and fifty-one male students in Turkey. Their ages ranged from nineteen to thirty-two $($ Mean $=22.6$ years with standard deviation $=2.3$ years). In Study 3 , there were fifty-five participating students, twenty-five female and thirty male. Their ages ranged from eighteen to twenty-five (Mean $=19.3$ years with standard deviation $=1.9$ years).

We reiterated that all participants could withdraw at any time and that their confidentiality would be faithfully protected. All participants confirmed their willingness to participate in this research and completed the survey form. According to the regulations of the research ethics committee of the university, researchers are exempt from their obligation to obtain ethics approval from the committee providing the following conditions are met: 1) participation is voluntary; 2) participants' privacy is protected; 3) participants are fully informed and grant consent prior to participation; and 4) the results of the study have no harmful effects on individuals or the community. The content and survey items of this research conform to the ethical principles of the university.

\subsection{Materials}

The questionnaire contained fourteen items of the persona scale and general demographic information. It was designed to be anonymous, and the cover letter reaffirmed that all information provided by the participants would remain confidential. The purpose of the study, contact information, and the identity and affiliation of the researcher were all explained in the cover letter.

Study 1 began with an exploratory factor analysis to estimate the dimensionality of persona. Study 2 used correlation analysis and factor analysis to identify the validity of the scale.

\section{Results}

\section{Study 1}

The goal of study 1 was to investigate the dimensionality of persona. An exploratory factor analysis was performed. The results of the scree test revealed a four-factor solution for this scale. A principal-component factor analysis with Varimax rotation was conducted to examine the validity of the construct. We applied the Kaiser-Meyer Olkin (KMO) test to measure whether our data were suited for factor analysis. The results showed that the KMO was .74 larger than required for factor analysis. A Bartlett's test indicated that the correlation between items was significant at $p<.001$ (Approx. Chi-Square $=2088.213$ ). The Cattel's scree test (not shown in this paper) indicated that there could be a four-factor solution that would support the literature based on our assumptions. 
The eigenvalue of the first factor was equal to 4.686, and it explained $33.5 \%$ of the variance. Based on the variables loading highly loading Factor", we titled it "Social masks" (I have multiple social masks for different social settings to protect my own interests). The second factor was equal to 2.120 (14.1\% of variance). Based on the variables loading highly onto Factor2, we called it "Identity" (I forfeit my personal identity to achieve the multiple desired roles in social and personal areas). The third factor was equal to 1.591 (11.4\% of variance). We called it "Social Influence" (I act like people who were influential in creating my personality). The fourth factor was equal to 1.121 (8.0\% of variance). Based on the variables loading highly onto Factor 4, we labeled it "Role" (I live with my social roles). The total variance of 67.9 was achieved from these four factors.

The eigenvalue of the first factor was equal to 4.686 , and it explained $33.5 \%$ of the variance. The second factor was equal to 2.120 (14.1\% of variance). The third factor was equal to 1.591 (11.4\% of variance). The fourth factor was equal to 1.121 (8.0\% of variance). The total variance of 67.9 was achieved from these four factors. The fifth factor's eigenvalue was equal to .873. According to Kaiser's (1974) criterion (eigenvalues greater than 1.0), this resulted in a four-factor solution. We present the item loading of the first unrotated factor in Table 1 . The

Table 1. Factor analysis for the persona scale $(N=226)$.

\begin{tabular}{|c|c|c|c|c|}
\hline \multirow[b]{2}{*}{ ITEM NO } & \multicolumn{4}{|c|}{ Component } \\
\hline & $\begin{array}{l}\text { Social } \\
\text { masks }\end{array}$ & Identity & $\begin{array}{c}\text { Social } \\
\text { Influence }\end{array}$ & Role \\
\hline $\begin{array}{l}\text { I have multiple social masks for different social settings to protect } \\
\text { my own interests. }\end{array}$ & .86 & & & \\
\hline To gain my friends' trust, I act the way they want me to act. & .83 & & & \\
\hline $\begin{array}{l}\text { I hide my personality from public view to avoid social rejection } \\
\text { and disapproval. }\end{array}$ & .78 & & & \\
\hline $\begin{array}{l}\text { I forfeit my personal identity to achieve the multiple desired roles } \\
\text { in social and personal areas. }\end{array}$ & & .82 & & \\
\hline I present myself to others in a fashion that they believe I should. & & .72 & & \\
\hline $\begin{array}{l}\text { I mask my personality with different social identities to reach my } \\
\text { goals. }\end{array}$ & & .71 & & \\
\hline $\begin{array}{l}\text { I have no difficulty playing the expected professional role, thanks } \\
\text { to my experience. }\end{array}$ & & .60 & & \\
\hline I act like people who were influential in creating my personality. & & & .77 & \\
\hline My behavior is largely molded by society. & & & .75 & \\
\hline I act like persons I idolize. & & & .72 & \\
\hline I am motivated by social acceptance to maintain feelings of worth. & & & .69 & \\
\hline I live with my social roles. & & & & .84 \\
\hline $\begin{array}{l}\text { The role of my career dominates all other roles and } \\
\text { responsibilities, especially the need to take care of myself. }\end{array}$ & & & & .76 \\
\hline $\begin{array}{l}\text { I adapt my expectations to comply and thus improve my social } \\
\text { acceptance. }\end{array}$ & & & & .73 \\
\hline
\end{tabular}


smallest loading item was .60, with all items of the scale over .50. This conforms to Hair, Sarstedt, Ringle, and Gudergan (2018) who suggest that the value loading factor should be higher than .50 .

The correlations among factors are shown in Table 2. Internal consistency reliability of the fourteen-item questionnaire was estimated using Cronbach's alpha $(\alpha=.84)$. The Cronbach's alpha of subscales ranged from .85 to .72 . These results confirm that the internal consistency of the persona scale and its subscales were adequate (Cortina, 1993). Table 2 presents the correlations among factors.

\section{Study 2}

The main goal of Study 2 was to assess test-retest reliability and its external validity. In Study 2, the external validity of the scale was estimated. The results of factor analysis for Studies 1 and 2 were almost identical in terms of the loading for all items. The results of the two samples show that there were four factor solutions for the persona scale. These results indicate acceptable generalizability of the scale and the factor solution was good. In the Study 2 sample, the four factor solutions explained $70 \%$ of the total variance. The internal consistency of the persona scale was .79. Cronbach's alpha for the subscale of the social mask was .89 , for social influence (.78), identity (.76), and role (.77) (see Table 3 ). These results show that the factor solution of the persona scale is good (Cortina, 1993).

Table 2. Means, standard deviations, scale reliability, and correlations $(N=226)$ of study 1 .

\begin{tabular}{|c|c|c|c|c|c|c|c|}
\hline \multirow[b]{2}{*}{ Factors } & \multirow[b]{2}{*}{ M } & \multirow[b]{2}{*}{$\mathrm{SD}$} & \multicolumn{5}{|c|}{ Correlation $(r)$} \\
\hline & & & Persona & 1 & 2 & 3 & 4 \\
\hline Persona & 2.7 & .68 & $(.85)$ & & & & \\
\hline Social masks & 2.2 & .97 & .73 & $(.85)$ & & & \\
\hline Identity & 2.7 & .98 & .80 & .55 & $(.76)$ & & \\
\hline Social influence & 2.9 & .84 & 69 & .35 & .31 & $(.74)$ & \\
\hline Role & 2.9 & .92 & .61 & 22 & .30 & .28 & $(.72)$ \\
\hline
\end{tabular}

Note. All correlations between subscales, $p<.001$. Cronbach alpha on the diagonal.

Table 3. Means, standard deviations, and test -retest correlation, Cronbach's alpha and explained variance $(N=110)$.

\begin{tabular}{cccccc}
\hline Factors & M & SD & $\boldsymbol{r}^{*}$ & $\alpha$ & Explained of \%Variance \\
\hline Persona & 2.8 & .66 & .85 & .79 & .70 \\
Social masks & 2.3 & 1.1 & .82 & .89 & .34 \\
Identity & 2.6 & 1.2 & .81 & .78 & .16 \\
Social influence & 2.8 & .81 & .84 & .76 & .11 \\
Role & 3.0 & 1.0 & .80 & .77 & .9
\end{tabular}

${ }^{*} p<.001$. 


\section{Test-retest}

Four weeks later, the questionnaire was conducted a second time with Sample 2 (see Table 3 ) to assess test-retest reliability of the scale (Endler \& Parker, 1994). Test-retest correlation for the total scale was $.85(p<.001)$. Cronbach's alpha for the subscales were the following: social mask (.82), social influence (.81), role (.84), and identity (.80), $p<.001$. The results suggest that responses on the scale were stable (McCrae, Kurtz, Yamagata, \& Terracciano, 2011).

\section{Study 3}

The primary goal of Study 3 was to assess its validity. The criterion-related validity of the scale was estimated in this study. Burns et al. (2017) explain that criterion-related validity is used to predict future and current performance. It shows the relationship between the scale and a measurable criterion. In this study, peer evaluation was used to estimate the criterion-related validity (see Appendix 1).

The reason for applying the peer evaluation method is that peers are familiar with each other in real life. University students tend to know each other well. Most campus chats evolve around their friends; therefore, peer ratings can be useful for obtaining valid personality information (Paunonen \& O'Neill, 2010). A peer evaluation can take several different forms depending upon its implementation (Panadero, Andrade, \& Brookhart, 2018). Vazire and Mehl's (2008) study reported their use of personality peer reports for increased validity as they tend to be free of certain distortional influences that can affect self-reporting.

The questionnaire was given to Sample 3 with four questions that presumed the dimensions of scale. The correlation between the self-rating persona scale and peer-reports was $r=.73, p<.001$, two tailed test (see Table 4). Regarding its subscales, the correlation between self-rating and peer-reports were the following: social mask $(r=.69)$, identity $(r=.74)$, social influence $(r=.71)$, and role $(r$ $=.76), p<.001$, two tailed test. Paunonen and O'Neill (2010) noted that a correlation between self-rating and peer-reports of $r=.70$ is high enough to validate measurement. Therefore, the scale is validated.

\section{Discussion}

For this research, we developed a reliable and valid scale for evaluating persona. Both studies indicated that a four-factor model fit the data with fourteen items.

Table 4. The correlation between the self-rating persona scale and peer-reports.

\begin{tabular}{ccc}
\hline Factors & $\boldsymbol{r}$ & $p<$ \\
\hline Persona & .73 & .001 \\
Social masks & .69 & .01 \\
Identity & .74 & .001 \\
Social influence & .71 & .001 \\
Role & .76 & .001. \\
\hline
\end{tabular}


The subscales of the persona were labelled "social mask" (3), "identity" (4), "social influence" (4), and "role" (3). The third study was performed to evaluate the criterion validity of the persona scale. The correlation between peer ratings and the persona scale was positive, as expected. The internal consistency of the persona scale indicated that this scale was satisfactorily reliable. The results of the test-retest suggested that responses on the scale were stable.

\subsection{Limitations}

Despite the contributions this study makes to the field, it has limitations. First, the data obtained from the Turkish bank employees may not be generalizable. To increase our confidence in the generalizabilty of the study, two different samples with this scale were used and yielded the same results.

With regard to generalizability, the findings of this research are limited to provide more credence to the validity of the persona scale. Persona scales can be studied using the larger samples in different places. Second, although the snowball sampling technique is widely used in social science, it may lead to selection bias.

\subsection{Conclusion and Future Studies}

The most important contribution of this research to the theory of persona is the explanation of the dimension of persona. The findings also have practical implications. What roles do organizations, or the general society play in defining persona personalities? How might a high or low persona rating affect the organization in terms of factors such as creativity, harmony, or negotiating ability? This scale may be helpful in investigating these questions.

A persona emphasizes certain aspects of social interactions to create a specific business situation. From a managerial perspective, for example, it would be interesting to use the scale to analyze the levels of personas before and after managerial appointments. In addition, the differences in personas between minorities and majorities can be investigated within an organization. Traditionally, managers are predominantly men. For this reason, the differences in personas between genders could also be evaluated, as well as other organizational factors that may affect possible differences. In a related vein, future research may wish to examine how facets of persona affect political involvement in particular culture.

\section{Conflicts of Interest}

The author declares no conflicts of interest regarding the publication of this paper.

\section{References}

An, J., Kwak, H., \& Jansen, B. J. (2017). Personas for Content Creators via Decomposed Aggregate Audience Statistics. Proceedings of Advances in Social Network Analysis and Mining (ASONAM, 2017), Sydney, July 2017, 632-635. 
https://doi.org/10.1145/3110025.3110072

Arendt, H. (2000). The Public and the Private Realm. The Portable Hannah Arendt. Peter Baehr (Ed.). New York: Penguin, 182-230.

Baber, K. M., \&Tucker, J. C. (2006). The Social Roles Questionnaire: A New Approach to Measuring Attitudes toward Gender. Sex Roles, 54, 459-467. https://doi.org/10.1007/s11199-006-9018-y

Baird, B. M., Le, K., \& Lucas, R. E. (2006). On the Nature of Intraindividual Personality Variability: Reliability, Validity, and Associations with Well-Being. Journal of Personality and Social Psychology, 90, 512-527. https://doi.org/10.1037/0022-3514.90.3.512

Barbara, S. (2018). Understanding the "Mask" in Autism: Girls' Perspectives and the Impact of Wearing It. Good Autism Practice, 19, 5-13.

Biddle, B.J. (1986). Recent Developments in Role Theory. Annual Review of Sociology, 12, 67-92. https://doi.org/10.1146/annurev.so.12.080186.000435

Biernacki, P., \& Waldorf, D. (1981). Snowball Sampling-Problems and Techniques of Chain Referral Sampling. Sociological Methods \& Research, 10, 141-163. https://doi.org/10.1177/004912418101000205

Bourdieu, P. (2005). The Social Structures of the Economy. Cambridge, UK: Polity Press.

Broady, T. (2015). The Carer Persona: Masking Individual Identities. Persona Studies, May, 65-75. https://doi.org/10.21153/ps2015vol1no1art392

Budner, S. (1962). Intolerance of Ambiguity as a Personality Variable. Journal of Personality, 30, 29-50. https://doi.org/10.1111/j.1467-6494.1962.tb02303.x

Burger, J. M. (2001). Social Influence, Psychology of. In International Encyclopedia of the Social \& Behavioural Sciences, 14320-14325.

https://www.sciencedirect.com/topics/social-sciences/social-influence https://doi.org/10.1016/B0-08-043076-7/01805-2

Burns, G. N., Morris, M. B., Periard, D. A., LaHuis, D., Flannery, N. M., Carretta, T. R., \& Roebke, M. (2017). Criterion-Related Validity of a Big Five General Factor of Personality from the TIPI to the IPIP. International Journal of Selection and Assessment, 25, 213-222. https://doi.org/10.1111/ijsa.12174

Cortina, J. M. (1993). What Is Coefficient Alpha? An Examination of Theory and Applications. Journal of Applied Psychology, 78, 98-104. https://doi.org/10.1037/0021-9010.78.1.98

Darby, S., \& Chatterton, P. (2019). Between and beyond Social Entrepreneur and Activist: Transformative Personas for Social Change. ACME: An International Journal for Critical Geographies, 18, 724-750.

De Gere, D. (2008). The Face of Masking: Examining Central Tendencies and Between-Person Variability in Display Management and Display Rule. Dissertation, Seattle, WA: University of Washington.

del Río-Lozano, M., et al. (2013). Gender Identity in Informal Care: Impact on Health in Spanish Caregivers. Qualitative Health Research, 23, 1506-1520. https://doi.org/10.1177/1049732313507144

Endler, N. S., \& Parker, J. D. A. (1994). Assessment of Multidimensional Coping: Task, Emotion, and Avoidance Strategies. Psychological Assessment, 6, 50-60. https://doi.org/10.1037/1040-3590.6.1.50

Fearon, J. D. (1999). What Is Identity (as We Now Use the Word)? https://web.stanford.edu/group/fearon-research/cgi-bin/wordpress/wp-content/upload s/2013/10/What-is-Identity-as-we-now-use-the-word-.pdf 
Friess, E. (2012). Personas and Decision Making in the Design Process: An Ethnographic Case Study. In Proceedings of the SIGCHI Conference on Human Factors in Computing Systems, CHI 12 (pp. 1209-1218). New York: ACM. https://doi.org/10.1145/2207676.2208572

Gergen, K. J. (1972). Social Psychology as History. Journal of Personality and Social Psychology, 26, 309-320. https://doi.org/10.1037/h0034436

Goffman, E. (1959). The Presentation of Self in Everyday Life. Garden City, NJ: Anchor Books.

Goodwin, K. (2009). Designing for the Digital Age: How to Create Human-Centered Products and Services. Indianapolis, IN: Wiley.

Griffith, G. M., \& Hastings, R. P. (2014). “He’s Hard Work, but He’s Worth It”. The Experience of Caregivers of Individuals with Intellectual Disabilities and Challenging Behavior: A Meta-Synthesis of Qualitative Research. Journal of Applied Research in Intellectual Disabilities, 27, 401-419. https://doi.org/10.1111/jar.12073

Haakonssen, K. (2014). The Philosophy of a Persona. History of European Ideas, 40, 116-121. https://doi.org/10.1080/01916599.2013.784051

Hair, J. F., Sarstedt, M., Ringle, C. M., \& Gudergan, S. P. (2018). Advanced Issues in Partial Least Squares Structural Equation Modeling (PLS-SEM). Thousand Oaks, CA: Sage. https://doi.org/10.3926/oss.37

Higgins, M., \& McKay, F. (2015). Gender and the Development of a Political Persona: The Case of Scottish First Minister Nicola Sturgeon. British Politics, 11, 283-300. https://doi.org/10.1057/bp.2015.44

Hillman, J. (1992). The Myth of Analysis: Three Essays in Archetypal Psychology. New York: Harper Perennial.

Hogg, M. A., Abrams, D., \& Brewer, M. B. (2017). Social Identity: The Role of Self in Group Processes and Intergroup Relations. Group Processes \& Intergroup Relations, 20, 570-581. https://doi.org/10.1177/1368430217690909

Holtzblatt, K., Wendell, J. B., \& Wood, S. (2005). Rapid Contextual Design: A How-to Guide to Key Techniques for User-Centered Design. Amsterdam: Elsevier. https://doi.org/10.1145/1066348.1066325

Hopcke, R. H. (1995). Persona: Where Sacred Meets Profane. Boston, MA: Shambhala.

Hornung, J. B., Bandelow, N. C., \& Vogeler, C. S. (2019). Sciences: Integrating Knowledge and Practice to Advance. Human Dignity, 52, 211-231. https://doi.org/10.1007/s11077-018-9340-6

Hudson, W. C. (1978). Persona and Defense Mechanisms. Journal of Analytical Psychology, 23, 54-62. https://doi.org/10.1111/j.1465-5922.1978.00054.x

Izuma, K. (2017). Chapter 16: The Neural Bases of Social Influence on Valuation and Behavior. In Decision Neuroscience (pp. 199-209). |Cambridge, MA: Academic Press. https://www.sciencedirect.com/topics/social-sciences/social-influence https://doi.org/10.1016/B978-0-12-805308-9.00016-6

Jackson, D. (2017). Persona of Anime: A Depth Psychological Approach to the Persona and Individuation. Dissertation, California: Faculty of Pacifica Graduate Institute.

Jung, C. G. (1966). The Collected Works of C. G. Jung (Vol. 7, 2nd ed.). Princeton, NJ: Princeton University Press.

Jung, C. G. (1971). Psychological Types The Collected Works (Volume 6). London: Routledge and Kegan Paul.

Jung, C. G. (2014). The Spirit in Man, Art, and Literature (Collected Works of C.G. Jung, Volume 15). C. G. Edited by Gerald Adler, \& R. F.C. Hull. 
https://doi.org/10.1515/9781400850884

Kaiser, H. F. (1974). An Index of Factorial Simplicity. Psychometrika, 39, 31-36. https://doi.org/10.1007/BF02291575

Khashe, S., Lucas, G., Becerik-Gerbera, B., \& Gratch, J. (2017). Full Length Article Buildings with Persona: Towards Effective Building-Occupant Communication. Computers in Human Behavior, 75, 607-618. https://doi.org/10.1016/j.chb.2017.05.040

Kirchherr, J., \& Charles, K. (2018). Enhancing the Sample Diversity of Snowball Samples: Recommendations from a Research Project on Anti-Dam Movements in Southeast Asia. PLoS ONE, 13, e0201710. https://doi.org/10.1371/journal.pone.0201710

Leary, M. R. (2003). Interpersonal Aspects of Optimal Self-Esteem and the Authentic Self. Psychological Inquiry, 14, 52-54. https://doi.org/10.1207/S15327965PLI1403\&4_15

Maria, J., \& Sandoval, M. (2008). Gender Differences in the Construction and Experience of Cancer Care: The Consequences of the Gendered Positioning of Careers. https://www.tandfonline.com/author/Barbour\%2C+Kim

Marshall, D. P., Moore, C., \& Borbour, K. (2015). Persona as Method: Exploring Celebrity and the Public Self through Persona Studies. Psychology \& Health, 23, 945-996.

Maslow, A. (1968). Toward a Psychology of Being. New York: Van Nostrand Reinhold.

McCrae, R. R., Kurtz, J. E., Yamagata, Y., \& Terracciano, A. (2011). Internal Consistency, Retest Reliability, and Their Implications for Personality Scale Validity. Personality Social Psychological Review, 15, 28-50. https://doi.org/10.1177/1088868310366253

Miller-Carpenter, S. (2018). Ten Steps in Scale Development and Reporting: A Guide for Researchers Communication Methods and Measures, 12, 25-44. https://doi.org/10.1080/19312458.2017.1396583

Millington, G (1982). Measuring Attitudes to Social Work: The Social Acceptance Questionnaire. Journal of Further and Higher Education, 6, 48-53. https://doi.org/10.1080/0309877820060206

Nario-Redmond, M. R., Biernat, M., Eidelman, S., \& Palenske, D. J. (2004). The Social and Personal Identities scale: A Measure of the Differential Importance Ascribed to Social and Personal Self-Categorizations. Self and Identity, 3, 143-175. https://doi.org/10.1080/13576500342000103

Nash, J. E., \& Calanico, J. M. (1996). The Meaning of Social Interaction. An Introduction to Social Psychology. Oxford: General Hall.

Oyd, I. R., Jones, M. C., \& Twidale, M. B. (2008). Resolving Incommensurable Debates: A Preliminary Identification of Persona Kinds, Attributes, and Characteristics. Artifact, 2, 12-26. https://doi.org/10.1080/17493460802276836

Panadero, E., Andrade, H., \& Brookhart, S. M. (2018). Fusing Self-Regulated Learning and Formative Assessment: A Roadmap of Where We Are, How We Got Here, and Where We Are Going. The Australian Educational Researcher, 45, 13-31. https://doi.org/10.1007/s13384-018-0258-y

Paulhus, D. L., \& Malcolm, C. L. (1988). Functional Flexibility: A New Conception of Interpersonal Flexibility. Journal of Personality and Social Psychology, 55, 88-101. https://doi.org/10.1037/0022-3514.55.1.88

Paunonen, S. V., \& O'neill, T. A. (2010). Self-Reports, Peer Ratings and Construct Validity, European Journal of Personality, 24, 189-206. https://doi.org/10.1002/per.751

Robinson, O. C. (2009). On the Social Malleability of Traits: Variability and Consistency in Big 5 Trait Expression across Three Interpersonal Contexts. Journal of Individual Differences, 30, 201-208. https://doi.org/10.1027/1614-0001.30.4.201

Rogers, C. R. (1959). A Theory of Therapy, Personality, and Interpersonal Relationships: 
As Developed in the Client-Centered Framework. In S. Koch (Ed.), Psychology: A Study of a Science. Formulations of the Person and the Social Context (Vol. 3, pp. 184-256). New York: McGraw Hill.

Salminen, J., Jansen, B. J., An, J., Kwak, H., \& Jung, S. G. (2018). Are Personas Done? Evaluating the Usefulness of Personas in the Age of Online Analytics. Persona Studies, 4, 47-65. https://doi.org/10.21153/psj2018vol4no2art737

Stemler, S. E. (2004). A Comparison of Consensus, Consistency, and Measurement Approaches to Estimating Inter-Rater Reliability. Practical Assessment, Research, and Evaluation, 9, Article 4. http://pareonline.net/getvn.asp?v=9\&n=4

Vazire, S., \& Mehl, M. R. (2008). Knowing Me, Knowing You: The Accuracy and Unique Predictive Validity of Self-Ratings of Daily Behavior. Journal of Personality and Social Psychology, 95, 1202-1216. https://doi.org/10.1037/a0013314

Wilson, C. (2009). User Experience Re-Mastered (eBook). Burlington, MA: Morgan Kaufmann.

Yurtsever, G. (2008). Negotiator's Profit Predicted by Cognitive Appraisal, Suppression of Emotions, Misrepresentation of Information, and Tolerance of Ambiguity. Perceptual and Motor Skills, 106, 590-608. https://doi.org/10.2466/pms.106.2.590-608

Zimbardo, P., Haney, C., Banks, C. W., \& Jaffe, D. (1971). Stanford Prison Experiment. https://web.stanford.edu/dept/spec_coll/uarch/exhibits/Narration.pdf 


\section{Appendix 1}

One week ago, students were informed that they would participate in a research on persona. They also attended a two-hour seminar on persona. The candidate was informed that they would not be given any details about the participants.

During peer evaluation for the persona scale, each time a student was chosen by a classmate as fitting questions $1,2,3$, or 4 , he/she scored a point on the scale. The total scores for each student on each question were computed. We then computed each question score to reach a total score for each student, after which the correlations between peer ratings and the persona scale scores were analyzed (Budner, 1962; Yurtsever, 2008).

The questions were as follows:

1) Among your classmates, who always uses a social mask to protect her/his own interests?

2) Among your classmates, who always conceals her/his identity from public view to avoid social rejection?

3) Among your classmates, who always creates alternative roles to improve social acceptance?

4) Among your classmates, who always looks for social influence to maintain feelings of worth?

\section{Appendix 2. The Scale Items Based on the Literature}

\begin{tabular}{|c|c|c|}
\hline Item no & References & Items \\
\hline 1 & Jung (1966) p. 41 & My behaviors are largely moulded by society. \\
\hline 2 & Jung (1971) p. 218 & I present myself to others in a fashion that they believe I should. \\
\hline 3 & Jung, C. G. (1971) p. 218 & I act like persons I idolize. \\
\hline 4 & Hudson, W. C. (1978) p. 57 & $\begin{array}{l}\text { I adapt my expectations to comply in order to improve my } \\
\text { social acceptance. }\end{array}$ \\
\hline 5 & Hudson, W. C. (1978) p. 56 & $\begin{array}{l}\text { I mask my personality with alternative social identities to help } \\
\text { reach my goals. }\end{array}$ \\
\hline 6 & Jung, C. G. (1966) p. 194 & $\begin{array}{l}\text { I am motivated by social acceptance to maintain feelings of } \\
\text { worth. }\end{array}$ \\
\hline 7 & Jung, C. G. (1966) p.194 & I live with my social roles. \\
\hline 8 & $\begin{array}{l}\text { del Río-Lozano et al. (2013) } \\
\text { p. } 1516\end{array}$ & $\begin{array}{l}\text { The role of my career dominates all other roles and } \\
\text { responsibilities, especially the need to take care of myself. }\end{array}$ \\
\hline 9 & $\begin{array}{l}\text { Griffith \&Hastings (2014) } \\
\text { p. } 412\end{array}$ & $\begin{array}{l}\text { I forfeit my personal identity to achieve the desired multiple } \\
\text { roles in social and personal areas. }\end{array}$ \\
\hline 10 & $\begin{array}{l}\text { Maria \& Sandoval (2008) p. } \\
954\end{array}$ & $\begin{array}{l}\text { I have no difficulty playing the expected professional role, } \\
\text { thanks to my experience. }\end{array}$ \\
\hline 11 & Gergen (1972) pp. $309-320$ & $\begin{array}{l}\text { I act like the people who have been influential in the } \\
\text { formation of my personality. }\end{array}$ \\
\hline 12 & Gergen (1972) pp. $309-320$ & $\begin{array}{l}\text { I hide my personality from public view to avoid social } \\
\text { rejection and disapproval. }\end{array}$ \\
\hline 13 & $\begin{array}{l}\text { Zimbardo, Haney, Banks, } \\
\text { \& Jaffe (1971) }\end{array}$ & $\begin{array}{l}\text { I have multiple social masks for different social settings to } \\
\text { protect my own interests. }\end{array}$ \\
\hline 14 & $\begin{array}{l}\text { Zimbardo, Haney, Banks, } \\
\text { \& Jaffe (1971) }\end{array}$ & $\begin{array}{l}\text { To gain my friends' trust, I act the way they want or expect } \\
\text { me to act. }\end{array}$ \\
\hline
\end{tabular}

